Łukasz Gemziak*

\title{
Profesor Dmitrij Lichaczow - świadek epoki, wybitny uczony, doktor honoris causa UMK
}

DOI: http://dx.doi.org/10.12775/LC.2021.027

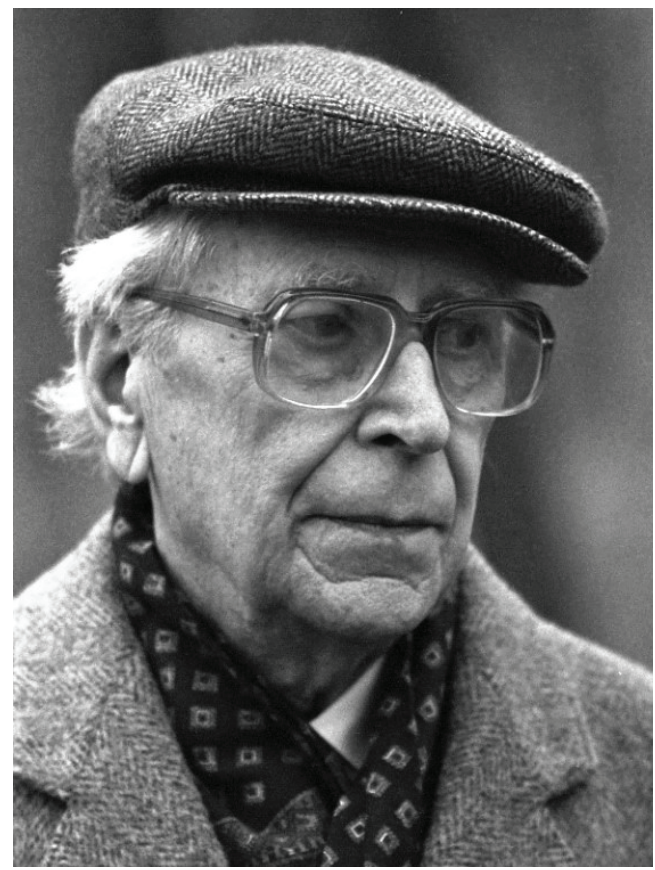

Prof. Dmitrij Siergiejewicz Lichaczow Амитрий Сергеевич $\Lambda$ ихаёв

Fot. Igor Palmin, Wikimedia Commons

* Rusycysta, slawista, literaturoznawca. Adiunkt w Katedrze Literatur Słowiańskich, Wydział Humanistyczny Uniwersytetu Mikołaja Kopernika w Toruniu.

E-mail: lukgem@umk.pl | ORCID: 0000-0002-7989-5139. 
rofesor Dmitrij Lichaczow ${ }^{1}$ (1906-1999), slawista, filolog i kulturoznawca, to jeden z najwybitniejszych przedstawicieli nauk humanistycznych minionego wieku. Autor fundamentalnych monografii dotyczących historii literatury i kultury był nie tylko uczonym, ale również świadkiem epoki oraz działaczem społecznym angażującym się w obronę dziedzictwa kultury rosyjskiej.

\section{Świadek XX wieku}

Burzliwe przemiany społeczno-polityczne, jakie dotknęły Rosję w XX wieku, stały się także udziałem Dmitrija Lichaczowa. Przyszły uczony był świadkiem rewolucji lutowej oraz październikowej w 1917 roku. W 1923 roku został studentem Piotrogrodzkiego Uniwersytetu Państwowego ${ }^{2}$. Za uczestnictwo w zebraniach studenckiej organizacji „Kosmiczna Akademia Nauk" oskarżono go o działalność kontrrewolucyjną i skazano. Od jesieni 1928 roku Lichaczow odbywał karę w Sołowieckim Obozie Specjalnego Przeznaczenia ${ }^{3}$. Dość nieoczekiwanie pobyt na Sołowkach umożliwił mu zaangażowanie się w działalność badawczą - współtworzył wydawane w obozie czasopismo, gdzie opublikował swój pierwszy artykuł naukowy. Po zakończeniu odbywania kary (w 1932 roku) Lichaczow pracował jako redaktor naukowy i korektor. W 1938 r. rozpoczął pracę w Instytucie Literatury Rosyjskiej Akademii Nauk ZSRR (później - Akademii Nauk Federacji Rosyjskiej). Z tą instytucją związany był do końca swojego życia. W latach 1941-1942 Lichaczow znajdował się w oblężonym Leningradzie, skąd udało mu się ewakuować wraz z rodziną w 1942 roku.

Okres powojenny to czas wytężonej pracy naukowej. Nie oznacza to jednak, że uczony pozostawał obojętny wobec otaczającej go rzeczywistości i nie musiał podejmować istotnych wyborów moralnych. W roku 1975 głosował przeciw wykluczeniu Andrieja Sacharowa z Akademii Nauk (dzień po głosowaniu ktoś napadł na Lichaczowa) (Arinsztejn 2006: 10). W okresie pierestrojki slawista prowadził aktywną działalność publicystyczną, zaś w latach 1989-1991 był deputowanym do najwyższego organu ustawodawczego w ZSRR Zjazdu Deputowanych Ludowych ZSRR. Również w Federacji Rosyjskiej pozostawał niezwykle zaangażowany społecznie.

\footnotetext{
1 Zgodnie z obowiązującymi w Polsce zasadami transkrypcji współczesnego alfabetu rosyjskiego nazwisko uczonego powinno się zapisywać jako „Lichaczow”. W niektórych publikacjach można jednak spotkać wariant "Lichaczew". Rozbieżność w zapisie dotyczy również imienia. Zgodnie z minionym już zwyczajem spolszczania imion w wielu zapisach bibliograficznych imię Lichaczowa brzmi „Dymitr”. Aktualnie dominuje tendencja do pozostawiania imienia w jego oryginalnym brzmieniu (po dokonaniu transkrypcji) - stąd "Dmitrij”. W przywoływanych w bibliografii i przypisach pozycjach zachowuję zapis z cytowanych publikacji. W efekcie w bibliografii można spotkać oba warianty imienia i nazwiska rosyjskiego badacza.

2 Od 1924 roku - kiedy Piotrogród przemianowano na Leningrad - był to Leningradzki Uniwersytet Państwowy.

3 Położony na największej z wysp archipelagu na Morzu Białym Monastyr Sołowiecki stał się miejscem, które posłużyło za prototyp dla systemu łagrów Gułag.
} 


\section{Działalność naukowa}

Jednym z najważniejszych tematów badawczych, któremu poświęcił się prof. Lichaczow, była literatura staroruska. Uczony zajmował się wieloaspektowym badaniem staroruskich latopisów - dużo uwagi poświęcił latopisom nowogrodzkim i kijowskim. W ramach studiów mediewistycznych dokonywał również krytycznego opracowania oraz przekładu na współczesny język rosyjski zabytków piśmiennictwa staroruskiego, w tym słynnej Powieści minionych lat. Slawista należał do grona badaczy innego wybitnego dzieła literackiego okresu średniowiecza - Stowa o wyprawie Igora. Oprócz prac nad historią literatury staroruskiej Lichaczow zajmował się także specyfiką stylu ówczesnych utworów oraz badał sposób, w jaki w tych dziełach portretowano człowieka.

Wśród innych zainteresowań naukowych uczonego warto wymienić rosyjski barok, kulturę śmiechu dawnej Rusi oraz wpływ spuścizny staroruskiej na współczesność. Pociągały go także teoretyczne aspekty badania dzieła literackiego, których znaczenie uwidacznia jego fundamentalna praca pt. Tekstologia (zob. Lichaczow 2001). O różnorodności zainteresowań slawisty świadczy jego książka o historii oraz estetyce sadów i ogrodów (zob. Lichaczow 1991).

Dla uczonego historia Rosji była nierozerwalnie związana z dziejami oraz kulturą Europy. Tę tezę udowadniał nie tylko w badaniach naukowych, ale również w pracach popularnonaukowych oraz publicystycznych. Według Lichaczowa dla rozwoju kultury i państwowości ruskiej wielkie znaczenie miały wpływy z Bizancjum (chrześcijaństwo) oraz Skandynawii (forma rządów). Znaczenie czynnika azjatyckiego było znikome ${ }^{4}$.

Ostatnia dekada życia Dmitrija Lichaczowa stanowiła podsumowanie jego badań i zainteresowań badawczych. W latach 90. XX pojawia się szereg książek (zob. np.: Lichaczow 1989; Lichaczow 1992), które - najczęściej w sposób popularnonaukowy - udostępniały i uogólniały dotychczasowe wyniki prac i przemyśleń uczonego z Sankt Petersburga.

\section{W obronie kultury}

Dmitrij Lichaczow działalność naukową udanie łączył z działalnością społeczną. Jego szczególną uwagę zajmowała troska o kulturę. Uczony brał udział w działaniach mających przyczynić się do zachowania lub odrestaurowania wielu obiektów kultury, zaś w latach 1986-1993 był przewodniczącym zarządu Radzieckiej (później: Rosyjskiej) Fundacji Kultury. Wyraz swojej dbałości o stan kultury dawał także w artykułach publicystycznych. Jego zdaniem kultura ma charakter narodotwórczy i musi być traktowana jako dobro wspólne. Dla podkreślenia doniosłości zadania, jakie stoi przed wszystkimi ludźmi, slawista ukuł termin „ekologia kultury” - dbanie o kulturę jest bowiem równie ważne jak dążenie do ochrony przyrody (Gemziak 2013: 358-359). Uczony przestrzegał przed zaniedbaniem tego obowiązku. Jednocześnie podkreślał, że należy dostrzegać pełnię zjawiska, jakim jest kultura: „Szczególnie

\footnotetext{
${ }^{4}$ Tę koncepcję Lichaczow określał mianem Skandosławii lub Skanobiznacjum. Szerzej na ten temat zob. Gemziak 2012.
} 
ważne wydaje mi się rozpatrywanie kultury jako pewnego organicznie jednolitego zjawiska, jako swego rodzaju sfery, w której istnieją wspólne dla różnych aspektów kultury tendencje, prawa, wzajemne przyciąganie i odpychanie...” (Lichaczow 2013: 369).

\section{Toruńskie ślady Lichaczowa}

Co ciekawe, losy autora fundamentalnych monografii dotyczących historii literatury rosyjskiej łączą się także z dziejami Uniwersytetu Mikołaja Kopernika. Toruńska uczelnia, jako pierwsza w Polsce, przyznała slawiście tytuł doktora honoris causa.

Pomysł nadania prof. Lichaczowowi tytułu doktora honoris causa zrodził się na Wydziale Humanistycznym UMK. Z takim wnioskiem wystąpił 24 czerwca 1964 roku prof. Konrad Górski ${ }^{5}$ podczas zebrania rady Wydziału Humanistycznego. W głosowaniu propozycję Górskiego poparli wszyscy członkowie rady wydziału. O uchwale został poinformowany rektor UMK (Cimochowski 1964). 29 września 1964 roku podczas zebrania senatu UMK odbyło się głosowanie dotyczące nadania slawiście tytułu doktora honoris causa. Wniosek uzyskał niemal jednogłośną akceptację (Protokół z ... $)^{6}$. Kwestie związane z zaproszeniem Lichaczowa do Torunia nadzorował ówczesny rektor UMK, prof. Antoni Swinarski, który prowadził w tej sprawie korespondencję z uczonym z Leningradu.

Wizyta prof. Lichaczowa w Toruniu miała się odbyć w listopadzie - taki termin zasugerowała w liście do rektora UMK prof. Maria Renata Mayenowa, badaczka literatury polskiej, dyrektor Instytutu Badań Literackich PAN w Warszawie (Mayenowa 1964). Mayenowa przyjęła na siebie rolę - ze względu na bliższą znajomość z Lichaczowem - pośrednika w kontaktach z toruńskim uniwersytetem.

Uroczystość planowana na listopad 1964 r. nie doszła jednak do skutku ${ }^{7}$ Zaproponowano więc nową datę: marzec 1965 r. W kolejnym liście do Dmitrija Lichaczowa rektor UMK upewniał się, czy taki termin mu odpowiada (Swinarski 1965). Leningradzki uczony odpowiedział, że postara się przyjechać w pierwszej połowie marca, należy wszelako brać pod uwagę, że - ponieważ uzyskanie zgody na wyjazd i załatwienie wszelkich formalności wymaga czasu - termin ten może się zmienić (Lichaczow 1965).

Data przyjazdu do Torunia nie uległa znaczącemu przesunięciu i 24 marca 1965 r. w auli ówczesnego Collegium Maximum na Rynku Staromiejskim ${ }^{8}$ odbyła się uroczystość wręczenia prof. Lichaczowowi tytułu doktora honoris causa. O wydarzeniu informowały lokalne gazety (zob. Tytuł doktora ... 1965: 1-2; Szósty doktorat... 1965: 1-2). Wśród zgromadzonych gości byli między innymi: ambasador ZSRR Gienadij Gołowienkow, attaché kulturalny ZSRR Konstanty Sajenko, dziekan Uniwersytetu Jagiellońskiego prof. Wiktor

5 Prof. Konrad Górski (1895-1990) - pierwszy dziekan Wydziału Humanistycznego UMK, historyk i teoretyk literatury, który specjalizował się w historii literatury polskiej. W 1981 r. został uhonorowany tytułem doktora honoris causa UMK.

${ }^{6} \mathrm{~W}$ protokole widnieje skreślony zapis, że wniosek został poparty jednogłośnie. Naniesiono poprawkę informującą, że jedna osoba wstrzymała się od głosu.

7 Nie natrafiłem na żadne informacje mówiące o powodach, dla których uroczystość wręczenia slawiście tytułu doktora honoris causa UMK ostatecznie nie doszła do skutku w listopadzie 1964 r.

8 Od 1949 roku Collegium Maximum mieściło się pod adresem Rynek Staromiejski 6, w budynku Dworu Artusa. 
Ректору университеря, мени Николея Коперника в Lоруне mporecсору доктору А. Свинерскому

2. 11.65.

\section{$9 / 2$}

1.убокоу важвемнт гостодин ректор!

由ше раз благодаро Вас за Ваше топ лашение. Постараюсь поиехать, как Ввт предлагаете, в перво половине марта. Пииу об этом в Иностраннти отдел Академии наук СССР. Разумеется, я не могу обешвгь, что $я$ точно приеду в предләгаемое Вами время, тан как оформление моего виезпа мохет потребовать времени.

с искренним и глубоким увежением

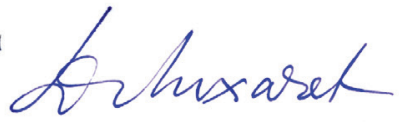

( член-горреспондент АН CCCP, пром. , доктор Д. јіихачев)

Relator h. Un.k wior.

inef. or A Swiuans:

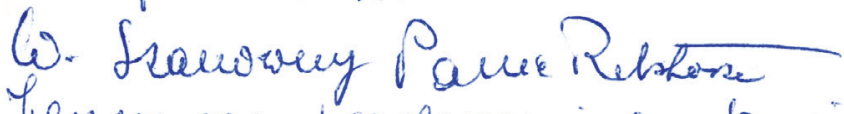

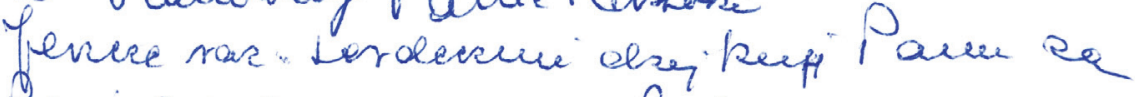

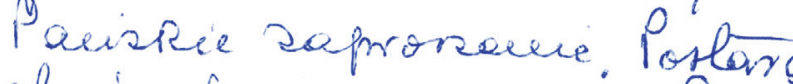

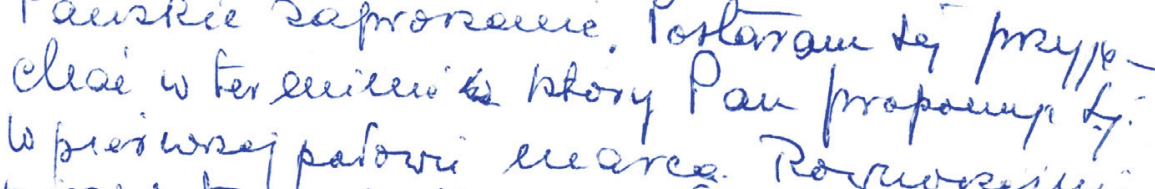
ring o tepu alo wy arsiars H ZS RR.

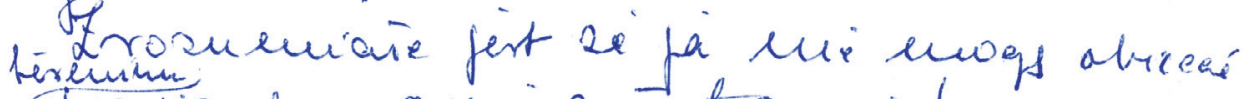

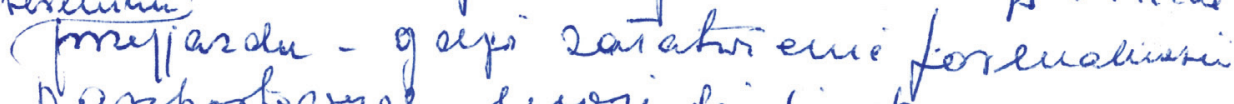

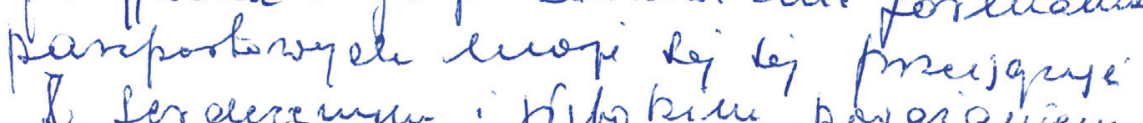

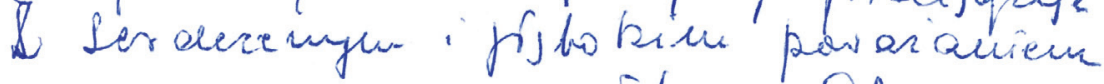
esithomes. Qt rave LSR? (7) Liehaesor

Odpowiedź Prof. Lichaczowa do Rektora UMK,

Prof. dr. inż. Antoniego Swinarskiego, w sprawie przyjazdu do Torunia

Źródło: Archiwum UMK - sygn. SKR-35/25 


\section{NOS \\ RECTOR ET SENATUS}

UNIVERSTTATIS COPERNICANAE THORUNENSIS

IN SOLLEMNEM CONVENTUM INVITAMUS

QUO IN CONVENTU DOMINUS CLARISSIMUS

DEMETRIUS SERGII FILIUS LICHACZEW

LITTERARUM DOCTOR, LITTERARUM RUSSICARUM IN UNIVERSITATE LENINGRADENSI

IN RUSSIA PROFESSOR, ACADEMIAE SCIENTIARUM AC LITTERARUM

FOEDERATARUM SOCIALISTARUM CONCILIORUM CIVITATUM SODALIS EPISTULARUM COMMERCIO IUNCTUS

DOCTORIS HONORIS CAUSA

TITULO RITE ORNABITUR

CONVENTUS IN AULA COLLEGII MAXIMI UNIVERSITATIS COPERNICANAE THORUNII IN FORO VETERI

ANTE DIEM IX KALENDAS APRILES ANNI MCMLXV HORA XI CUM DODRANTE HABEBTTUR

*

REKTOR I SENAT
UNIWERSYTETU MIKOEAJA KOPERNIKA W TORUNIU

ZAPRASZAJÄ NA

UROCZYSTOŚĆ NADANIA

TYTUEU DOKTORA HONORIS CAUSA

PROF. DR D. S. LICHACZEWOWI

DOKTOROWI NAUK FILOLOGICZNYCH, PROFESOROWI HISTORII

LITERATURY ROSY]SKIEJ UNIWERSYTETU $W$ LENINGRADZIE,

CZLONKOWI-KORESPONDENTOWI AKADEMII NAUK ZWIAZKU SOCJALISTYCZNYCH REPUBLIK RADZIECKICH

UROCZYSTOSC TA ODBĘDZIE SIE W DNIU 24 MARCA 1965 r. O GODZ. 11,45

W AULI COLLEGIUM MAXIMUM W TORUNIU, RYNEK STAROMIEJSKI

*

Zaproszenie na uroczystość

wręczenia Prof. Lichaczowowi tytułu doktora honoris causa

Źródło: Archiwum UMK - sygn. SKR-35/25 
Jakubowski (1965), prof. Mayenowa oraz prof. Janina Kulczycka, prorektor Uniwersytetu Warszawskiego (Szósty doktorat... 1965: 1).

Podczas uroczystości ówczesny dziekan Wydziału Humanistycznego, doc. dr Donald Steyer, przedstawił biografię Lichaczowa, zaś o jego dorobku naukowym mówił podczas laudacji prof. Konrad Górski. Toruński uczony odebrał także przyrzeczenie od leningradzkiego badacza. Promotor w następujący sposób zwrócił się do swojego doktoranta:

Czcigodny doktorancie -

[... znając zarówno Twój wybitny dorobek naukowy w dziedzinie historii literatury Twego narodu, jak i Twoją nieskazitelność w dążeniu do poznania prawdy, zapragnęliśmy uczynić Cię doktorem honoris causa naszej społeczności uniwersyteckiej.

Ale wpierw chcielibyśmy uzyskać Twoje przyrzeczenie, że pozostaniesz zawsze taki, jaki byłeś dotychczas i jakim pragnęlibyśmy Cię zawsze widzieć. [... ]

A więc nic nie stoi na przeszkodzie, abyśmy obdarzyli Cię godnością, której zapragnęliśmy Ci udzielić. Wobec tego ja - promotor rite constitutus - Ciebie Dymitra Siergiejewicza Lichaczewa - pochodzącego z Leningradu - doktorem honoris causa czynię, uczynionego ogłoszeniem i na dowód tego dyplom opatrzony pieczęcią naszego uniwersytetu Tobie doręczam (Górski 1965).

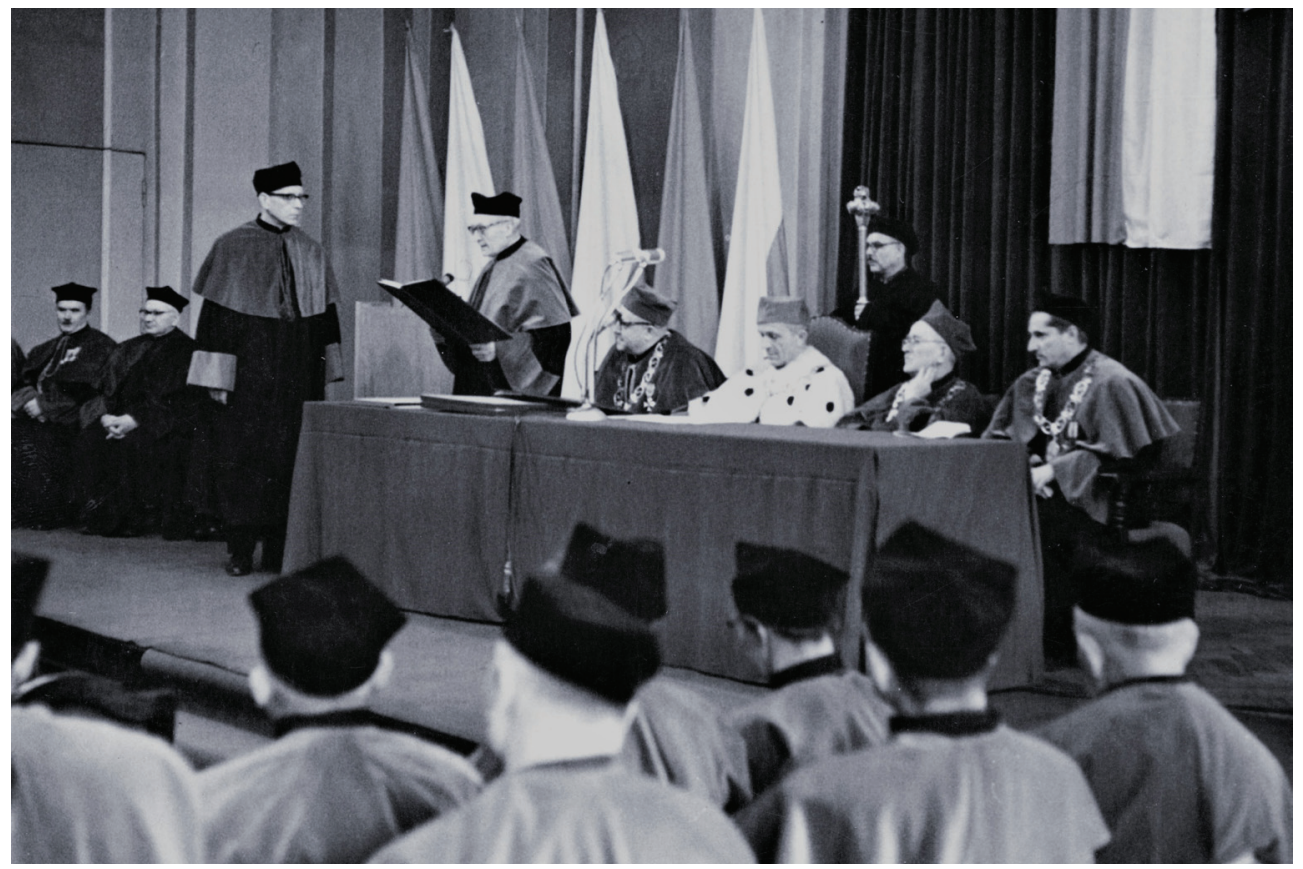

Laudacja z okazji nadania Prof. Lichaczowowi tytułu doktora honoris causa Fot. Alojzy Czarnecki; źródło: Archiwum UMK - sygn. SKR-35/25

Uroczystość wręczenia tytułu doktora honoris causa Dmitrijowi Lichaczowowi była bez wątpienia najważniejszym epizodem $w$ jego relacjach z UMK. Nie była wszakże jedynym zdarzeniem łączącym slawistę z toruńskim środowiskiem naukowym. Za szczególnie ważne należy uznać relacje łączące leningradzkiego uczonego z Konradem Górskim. Sam Lichaczow odnotował w komentarzu dla „Gazety Pomorskiej”: „Mam ścisłe kontakty z wieloma 
polskimi naukowcami, z prof. Konradem Górskim od kilku lat pracuję w komisji edytorsko-tekstologicznej Zjazdu Slawistów, gdzie prof. Górski pełni funkcję przewodniczącego, a ja wiceprzewodniczącego" (Lichaczew 1965: 4). Z kolei Górski w 1988 roku wspominał, że gdy gościł w Leningradzie, to właśnie Lichaczow oprowadzał go po wystawach ikon i tłumaczył zagadnienia związane z rozwojem malarstwa. Polonista zaznaczył także, że we wspomnianej Komisji Edytorsko-Tekstologicznej Zjazdu Slawistów przepracował z Lichaczowem 20 lat (Górski 1988: 1,11). O tym jak wielką estymą darzyli się nawzajem badacze może świadczyć to, iż w wydanej w 1967 roku księdze pamiątkowej ku czci prof. Górskiego znalazł się również artykuł autorstwa Lichaczowa (1967: 149-153).

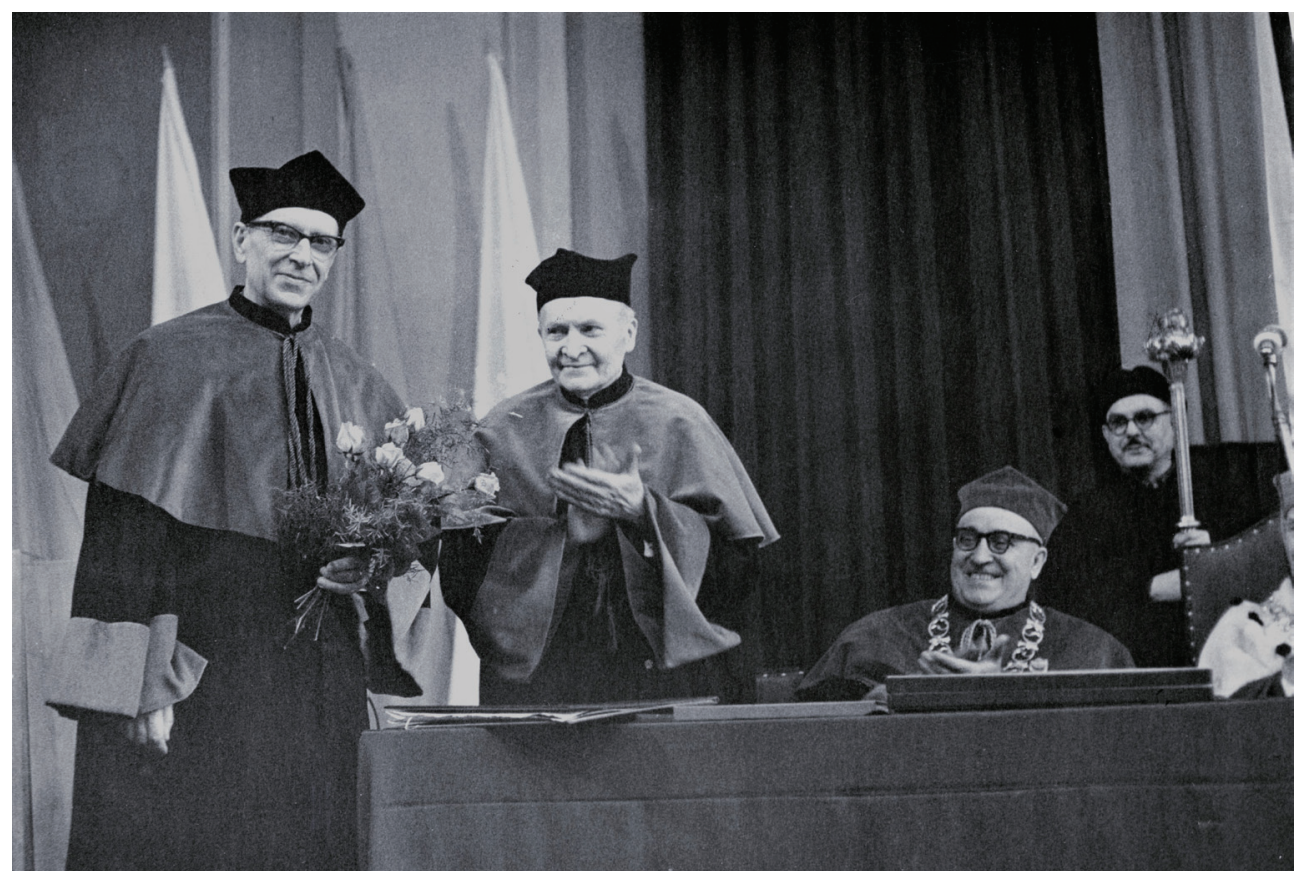

Aplauz po wręczeniu Prof. Lichaczowowi tytułu doktora honoris causa

Fot. Alojzy Czarnecki; źródło: Archiwum UMK - sygn. SKR-35/25

O profesorze Lichaczowie nie zapomniano w Toruniu i w latach późniejszych. W listopadzie 1986 r. z okazji 80. rocznicy urodzin uczonego odbyła się uroczysta sesja naukowa zorganizowana w Zakładzie Filologii Rosyjskiej UMK ${ }^{9}$. Artykuły powstałe na bazie wygłoszonych wówczas referatów ukazały się w toruńskim czasopiśmie. Warto nadmienić, że znalazła się wśród nich publikacja Elizy Małek, która szczegółowo charakteryzowała badawcze zainteresowania i dokonania Lichaczowa (zob. Małek 1990: 5-29). Do artykułu dołączona została bibliografia „prac Lichaczowa opublikowanych w latach 1961-1985 w Polsce, a także recenzji jego dorobku i innych publikacji propagujących dokonania Jubilata” (zob. Małek 1990: 25-29).

Pamięć o toruńskich śladach i naukowych dokonaniach wybitnego slawisty wciąż pozostaje żywa. Świadectwem tego jest zorganizowane przez UMK oraz Centrum

${ }^{9}$ Wydarzenie to odnotowała także lokalna prasa. Zob. Wawrzyńczak 1986: 5. 
Polsko-Rosyjskiego Dialogu i Porozumienia debata pt. „Miłość ojczyzny w dziele i życiu Dmitrija Lichaczowa a współczesna Rosja”. Wydarzenie miało miejsce 8 listopada 2016 roku w budynku Collegium Maius przy ulicy Fosa Staromiejska 3 i połączone było z prezentacją polskiego przekładu Wspomnień Lichaczowa (2016). Oprócz autora tłumaczenia, Bogusława Żyłki, udział w spotkaniu wzięli także inni goście. Aleksandr Kobak, dyrektor Fundacji im. D.S. Lichaczowa (Sankt-Petersburg) opowiadał o znaczeniu Leningradu/Sankt-Petersburga w życiu slawisty. Wnuczka Lichaczowa, profesor Uniwersytetu w Manchesterze, Wiera Tołc podzieliła się osobistymi wspomnieniami o swoim dziadku. Wystąpienia gości poprzedziła krótka prezentacja Łukasz Gemziaka o toruńskich śladach w życiu leningradzkiego uczonego, zaś za organizację spotkania oraz moderowanie dyskusji dotyczącej wybranych fragmentów Wspomnień odpowiadała Anna Skubaczewska-Pniewska.

\section{Bibliografia}

Arinsztejn, Leonid (red.) 2006. Nieizwiestnyj Lichaczow. Nieopublikowannyje matieriaty iz archiwa Rossijskogo fonda kultury. Moskwa: Rossijskij fond kultury.

Gemziak, Łukasz 2012. „Koncepcja Skandosławii Dymitra Lichaczowa”. Athenaeum. Polskie Studia Politologiczne 34: 185-202.

— 2013. „Koncepcja kultury Dymitra Lichaczowa”. Człowiek i Społeczeństwo XXXV, 2: 355-366.

Górski, Konrad 1988. „Białe plamy w mickiewiczologii”. Rozm. przepr. I. Maślińska. Życie Literackie 14: 1,11 .

Lichaczew, Dymitr 1965. „Mówi prof. D. S. Lichaczew”. Ilustrowany Kurier Polski 70: 4.

Lichaczow, Dmitrij 1967. „Zakon celnosti chudożestwiennogo izobrażenija w iskusstwie i litieraturie driewniej Rusi”. W: Artur Hutnikiewicz (red.). Księga pamiątkowa ku czci Konrada Górskiego. Toruń - Poznań: Towarzystwo Naukowe w Toruniu - Państwowe Wydawnictwo Naukowe.

— 1989. O fitołogii. Moskwa: Wysszaja szkoła.

- 1992. Russkoje iskusstwo ot driewnosti do awangarda. Moskwa: Iskusstwo.

— 2001. Tiekstołogija. Na matieriale russkoj litieratury X-XVII ww. Sankt-Pietierburg: Aletejia.

— 1991. Poezja ogrodów. O semantyce stylów ogrodowo-parkowych. Tłum. Kaja Natalia Sakowicz. Wrocław: Zakład Narodowy im. Ossolińskich.

— 2013. „Kultura jako jednolita sfera”. Tłum. Łukasz Gemziak. Człowiek i Społeczeństwo XXXV, 2: 367-377.

Małek, Eliza 1990. „Profesor Dymitr Lichaczow - doktor honoris causa Uniwersytetu Mikołaja Kopernika w Toruniu (w osiemdziesiątą rocznicę urodzin)". Acta Universitatis Nicolai Copernici. Nauki Humanistyczno-Spoteczne. Filologia Rosyjska 1: 5-29.

„Szósty doktorat honoris causa Uniwersytetu M. Kopernika. Wysokie wyróżnienie radzieckiego naukowca" 1965. Ilustrowany Kurier Polski 71: 1-2.

„Tytuł doktora h. c. dla prof. dr D.S. Lichaczewa” 1965. Gazeta Pomorska 71: 1-2.

Wawrzyńczak, Jan 1986. „Jubileusz prof. Dymitra Lichaczowa”. Gazeta Toruńska 279: 5. 


\section{Źródła archiwalne}

Cimochowski, Władysław 1964. List dziekana Wydziału Humanistycznego UMK, prof. dr Wactawa Cimochowskiego, do rektora UMK $z$ dnia 21 sierpnia $1964 r$. [Dokument oznaczony numerem 30]. Sygn. SKR-35/25, Nadawanie stopni doktora honoris causa UMK. Teczka prof. dr hab. Dymitra Lichaczowa. Archiwum Uniwersytetu Mikołaja Kopernika w Toruniu (dalej: AUMK).

Górski, Konrad 1965. Laudacja prof. Górskiego dla prof. Lichaczowa (rękopis). Zbiory profesora Konrada Górskiego. Archiwum Towarzystwa Naukowego w Toruniu.

Jakubowski, Wiktor 1965. List kierownika Katedry Filologii Rosyjskiej Uniwersytetu Jagiellońskiego, prof. dra Wiktora Jakubowskiego, do rektora UMK, prof. dra Antoniego Swinarskiego z 15 lutego $1965 r$. [Dokument oznaczony numerem 39]. Sygn. SKR-35/25, Nadawanie stopni doktora honoris causa UMK. Teczka prof. dr hab. Dymitra Lichaczowa. AUMK.

Lichaczow, Dymitr 1965. List prof. Dymitra Lichaczowa do rektora UMK, prof. dra Antoniego Swinarskiego $z 2$ lutego 1965 r. [Dokument oznaczony numerem 37]. Sygn. SKR-35/25, Nadawanie stopni doktora honoris causa UMK. Teczka prof. dr hab. Dymitra Lichaczowa. AUMK.

Mayenowa, Maria Renata 1964. List prof. dr M. R. Mayenowej do rektora UMK z dnia 7 lipca 1964 r. [Dokument oznaczony numerem 29]. Sygn. SKR-35/25, Nadawanie stopni doktora honoris causa UMK. Teczka prof. dr hab. Dymitra Lichaczowa. AUMK.

Protokót z posiedzenia Senatu UMK z dnia 29.09.1964 r. [Każdy protokół numerowany oddzielnie]. Protokoły posiedzeń Senatu UMK 1964/1965 - 1965/1966. AUMK.

Swinarski, Antoni 1965. List $z$ dnia rektora UMK, prof. dra Antoniego Swinarskiego do prof. Dymitra Lichaczowa $z 13$ stycznia 1965 r. [Dokument oznaczony numerem 35]. Sygn. SKR-35/25, Nadawanie stopni doktora honoris causa UMK. Teczka prof. dr hab. Dymitra Lichaczowa. AUMK. 